\title{
Nas trilhas dos livros e coletâneas: um ensaio bibliográfico
}

Lígia Wilhelms Eras

\section{Resumo}

A produção deste ensaio bibliográfico registra o balanço e a movimentação do subcampo do Ensino de Sociologia na Educação Básica revelando uma farta produção, em uma trajetória recente, temas e produções que revelam transições de olhares, maturação e as mudanças significativas inseridas na escola que desafiam o pensamento e a formação de professores nas esferas acadêmica e escolar.

Palauras-chave: Ensino de Sociologia. Educação Básica. Livros coletâneas.

Seguir as trilhas dos livros coletâneas sobre o Ensino de Sociologia na Educação Básica é um elemento ímpar de visualização da construção da história da educação nos capítulos particulares que descrevem um amplo processo de luta pelo retorno da Sociologia ao cenário da educaçáo escolar e do modo como foram desenhadas diversas sociologias nesse investimento de produzir conhecimento a partir da Sociologia na escola. Para além da análise crítica dos conteúdos, está o reconhecimento das diferentes trajetórias e contribuiçóes cujos autores não furtaram esforços de trazer ao espaço público o debate, as possibilidades, as limitaçóes de todo esse processo.

Os estudos de Villas Boas $(2007)^{1}$ representam um grande estímulo para pensar a análise sociológica em torno da produção de livros sobre Ciências Sociais no Brasil, pois priorizam a bibliografia como instrumento de abordagem. Contudo, essa autora menciona que a falta de ênfase à metodologia pode esvaziar o sentido do patrimônio materializado em pesquisas como índice de institucionalização do conhecimento científico. De acordo com Villas Boas (2007), as possíveis consequências do descaso do uso da bibliografia acumulada é a efetiva falta de informação sobre livros e revistas que poderiam conferir organicidade às discussōes. Em outras palavras, o desconhecimento sobre

VILLAS BOAS, G.. A vocação das Ciências Sociais no Brasil: um estudo da sua produção em livros do acervo da Biblioteca Nacional (1945 a 1966). Rio de Janeiro: Biblioteca Nacional, 2007. 
a produção bibliográfica cria uma barreira significativa para os avanços na área, tendo-se recorrentemente como diz a máxima, "inventar a pólvora".

Ao nos debruçarmos sobre a produção bibliográfica, revelamos quem somos e, a partir desse pressuposto, inferir "como a crítica sobre nós mesmos é uma atitude científica necessária à própria ciência”. Portanto, pela produção da análise acerca da condição bibliográfica sobre o Ensino de Ciências Sociais/ Sociologia na Educação Básica, é possível perceber que as marcas da intermitência são destaque às sistematizaçóes na área do Ensino de Sociologia Escolar; bem como, da sua militância.

$\mathrm{O}$ aumento das produçóes, que preservam, quase em sua totalidade, a produção da área e o sentido da coletividade - marcas de seu habitus e deste campo - na organizaçáo das obras, no estabelecimento das autorias e no destino dos livros coletâneas e na propagação de diferentes ideias coletivas: os licenciados e licenciandos em Ciências Sociais; os professores de Sociologia na Educação Básica; os estudantes de Ensino Médio; os professores pesquisadores sobre os temas relacionados ao Ensino de Ciências Sociais/Sociologia, os pares professores de disciplinas ligadas à formação de professores de Sociologia; os cursos de Ciências Sociais; os diferentes espaços de diálogo com diferentes áreas das Ciências Humanas e o campo do conhecimento dos saberes docentes e educacionais.

Nesse contexto, elaboramos a sistematização que contém 28 (vinte e oito) livros coletâneas ${ }^{2}$, específicos sobre o Ensino de Sociologia na Educação Básica

2 BRIDI, M. A.; ARAÚJO, S. M.; MOTIM, B. L. Ensinar e aprender Sociologia. São Paulo: Contexto, 20 I0; CAINELLI, M. R.; SILVA, I. F. (Org.). O estágio na licenciatura: a formação de professores e a experiência interdisciplinar na Universidade Estadual de Londrina. Londrina: UEL, 2009; CARVALHO, C. A. A Sociologia no Ensino Médio (Org.). Londrina: EDUEL, 20 I0; CARVALHO, L. M. G. (Org.). Sociologia e ensino em debate: experiências e discussão de sociologia no ensino médio. ljui: Ed. Unijuí, 2004; COLOGNESE, S. A (Org.). O desenvolvimento da Sociologia no oeste do Paraná. Tempo da Ciência, v. 12, n. 24, p. 145-160, $2^{\circ}$ sem. 2005; Fronteiras do saber sociológico. Porto Alegre: Evangraf, 2012;

Novas fronteiras

para o saber sociológico. Porto Alegre: Evangraf, 20I3; ERAS, L.; FEIJÓ, F. Por uma transposição didática das teorias das Ciências Sociais (Sociologia. Antropologia e Ciência Política): teorizações sobre as práticas de ensino em Ciências Sociais. In: Gonçalves, D. N. (Org.). Sociologia e Juventude no Ensino Médio: formação, PIBID e outras experiências. I. ed. Campinas: Editora Pontes, 2013, v. I, p. 87-99; FERREIRA, L. de F. G. (Org.). Subsídios para a educação em direitos humanos nas ciências sociais. João Pessoa: Editora Universidade da UFPB, 2010 ; FIGUEIRO, A. V.; OLIVEIRA, L. F.; PINTO, N. M. Sociologia na sala de aula: reflexões e experiências docentes no Estado do Rio de Janeiro. Rio de Janeiro: Imperial Novo Milênio, 20 I2; HANDFAS, A.; OLIVEIRA, L. F. (Org.). A Sociologia vai à escola. Rio de Janeiro: Quartet FAPERJ, 2009; $M A C ̧ A I R A$, J. P. Dilemas e perspectivas da Sociologia na Educação Básica. Rio de Janeiro: E-papers: 
(2004 a 2013) e em uma nova atualização para este ensaio, foram acrescentadas mais quatro obras 3 publicadas entres os anos de 2014 e 2015. O que é certo é que haverá, em um curso muito breve de tempo, novas publicaçóes cujas coletâneas ganharáo o formato de coleçóes de ensino de sociologia ${ }^{4}$.

Embora se saiba que também há outros livros produzidos por cursos de Licenciatura e/ou Bacharelado em Ciências Sociais, que apresentam temas correlatos ao espaço educacional, e uma grande leva de novas publicaçóes que serão editorados e lançados ao público, apenas se menciona a descrição dos livros que apresentam discussóes mais exclusivas às relaçôes de Ensino e Sociologia Escolar.

20I2; LIMA, A. M. de S. (Org.). As persistentes desigualdades brasileiras como temas para o Ensino Médio. Londrina: Eduel, 201।; ; ARAÚUO, A. L.; FERREIRA, J.; MOTTA, S. C. L. Sugestões didáticas

de Ensino de Sociologia. Londrina: UEL, 2012; MAESTRI, D. S. M. LDB, DCNs, PCNs e OCNs: uma discussão acerca do papel das Ciências Humanas e da Sociologia no Ensino Médio. In: MEIRELLES, M.; RAIZER, L.; PEREIRA, L. H. (Org.). $\mathbf{O}$ ensino de Sociologia no RS: repensando o lugar da Sociologia. Porto Alegre: Evangraf/LAVIECS, 2013; Mediações: Revista de Ciências Sociais - Dossiê Ensino de Sociologia, Londrina, $v$. I2, n. I, p. I45-I60, jan./jun. 2007; MEIRELLES, M.; RAIZER, L; PEREIRA, L. H (Org.). O ensino de Sociologia no RS: repensando o lugar da Sociologia. Porto Alegre: Evangraf/LAVIECS, 20 I3; MEUCCI, S. Institucionalização da Sociologia no Brasil: primeiros manuais e cursos. São Paulo: Hucitec: Fapesp, 20 II; MORAES, A. Explorando o Ensino Explorando - Sociologia. Ministério da Educação, Secretaria de Educação Básica, 20 I0. v. 15.; OLIVEIRA, D. D. (Org.). Sociologia e educação em direitos humanos. Goiânia: Fundação de Apoio à Pesquisa na UFG (FUNAPE), 20I0; Sociologia no ensino médio: experiências e desafios. Goiânia: Fundação de Apoio à Pesquisa na UFG (FUNAPE), 20I0; OLIVEIRA, L. F. (Org.). Sociologia na sala de aula: reflexões e experiências docentes no Estado do Rio de Janeiro. Rio de Janeiro: Imperial Novo Milênio, 20 I2; OLIVEIRA, M. de (Org.). As Ciências Sociais no Paraná. Curitiba: Protexto, 2006; MEUCCI, S. Institucionalização da Sociologia no Brasil: primeiros manuais e cursos. São Paulo: Hucitec: Fapesp, 20 II; PLANCHEREL, A. A.; OLIVEIRA, E. A. F (Org.). Leituras sobre Sociologia no Ensino Médio. Maceió: EDUFAL, 2007; RAMALHO, J. R.; SOUZA, R. de A (Org.). Pibid: Memórias de iniciação à docência. Campina Grande: Editora da UFCG, 2013; SANTOS, $A$. R. de J. (Org.). Práticas e reflexões de ensino e pesquisa do projeto PRODOCÊNCIA da UEL. Londrina: Universidade Estadual de Londrina, 20/2; SILVA, I. L. F. (Org.). Cadernos de metodologias de ensino e pesquisa de Sociologia: Lenpes laboratório de ensino, pesquisa e extensão de Sociologia. SETI-PR, 2009; SOUSA, F. P. (Org.). Sociologia conhecimento e ensino. Florianópolis: Editora em Debate, 2012.

3 VIEIRA, J. G. V.; CUNHA, L. A. Desafios e perspectivas do Ensino e da formação de Professores de Sociologia para o Ensino Médio. Mossoró: UERN, 20/4; LIMA, M. A. de S. (Org.). Estágio, formação e trabalho docente: experiências das jornadas/cursos do FOPE/PRODOCÊNCIA. Londrina: UEL, 2014; MEIRELLES, M.; RAIZER, L.; PEREIRA, L. H. (Org.). Diálogos entre Pedagogia e Sociologia. Porto Alegre: Evangraf/LAVIEC, 20I4; HANDFAS, A.; MAÇAIRA, J. P.; FRACA, A. B. Conhecimento Escolar e Ensino de Sociologia: instituições, práticas e percepções. Rio de Janeiro: 7 Letras, 2015.

4 É um projeto para o qual os organizadores, Mauro Meirelles, Leandro Raizer e Luiza Helena Pereira encaminham suas produções pela ótica da diversidade de manifestações de experiências didáticas, institucionais $e$ formativas no formato de uma coletânea específica para o Ensino de Sociologia com fomento do MEC. FNDE, SEB, LAVIECS, IFCH, FORPROF, SEAD, UFRCS. 
Então, o que podemos encontrar e esperar dos livros coletâneas?

I. É interessante antes destacarmos o locus de suas produções: a) do ponto de vista das autorias, há um encontro concatenado entre licenciandos, licenciados, professores de Sociologia na Educação Básica, pibidianos, pesquisadores, professores dos cursos de Licenciatura e Bacharelado em Ciências Sociais; b) também é preciso mencionarmos que, no estudo das trajetórias dos autores - em uma presença mais permanente nos debates -, há um envolvimento e um longo conhecimento de causa, cujas atuaçôes passaram por atuaçóes docentes em diferentes níveis de ensino (inclusive a Educação Básica), o que estende de modo muito rico e contextualizado os percursos identitários da escola para o momento da reflexáo, do pensamento e das práticas de ensino a partir das Ciências Sociais; c) o formato de coletâneas tem permitido aliar projetos institucionais e de eventos - no livro como recurso materializado - que permitem ampliar o acesso à circulação das ideias, inicialmente projetadas no espaço das escolas, nos laboratórios de ensino locais e a síntese dos eventos nacionais e estaduais da área; d) nas coletâneas, nós percebemos um esforço contínuo do entrelaçamento entre o espaço acadêmico e escolar e do momento diferenciado da formação, cujo fomento científico e de ensino é um diferencial no amadurecimento e em novas projeçóes do subcampo do ensino de sociologia na Educação Básica (considerando eventos, produçôes e arranjos institucionais de interlocução/laboratórios de ensino).

II. Uma Sociologia dos sociólogos que pensam a educação. Uma renovada indagação sobre o processo de formação dos cientistas sociais para a pesquisa e para o ensino, o que geraria o encontro entre as duas atuaçóes/"vocaçóes": a do cientista e a do professor no espaço das Ciências Sociais. A metalinguagem e as metanarrativas são um convite permanente, e as rodas de discussóes primam por identificar os efeitos da intermitência sobre o subcampo do ensino, o que um sociólogo pode fazer abrangendo o campo educacional, as arestas do subcampo no entremeio entre a escola e a universidade e a prática de ensino como o núcleo de descobertas em um permanente laboratório que, no substrato da escola e das novas sociabilidades, sobretudo, os que se relacionam ao público jovem-adolescente atual - exige mais do ponto de vista didático, lúdico, tecnológico e mesmo na operação da teorização das transposiçóes didáticas no ensino para as licenciaturas, bacharelados e para as pesquisas na pós-graduação. 
III. Com relação aos temários, há um grande leque de estudos-temas em que é possível identificar doze unidades de conteúdos relevantes à construção dos conhecimentos recentes: 1) Estudos sobre a História do Ensino de Sociologia/Ciências Sociais na Educação Básica; 2) Estudos e os fundamentos teórico-epistemológicos sobre o Ensino de Sociologia/Ciências Sociais na Educação Básica; 3) Estudos sobre o currículo e o Ensino de Sociologia; 4) Estudos sobre Metodologias e Didáticas do Ensino de Sociologia/Ciências Sociais; 5) Estudos sobre as experiências de Ensino de Sociologia; 6) Estudos sobre as Licenciaturas em Ciências Sociais e a formação de professores; 7) Estudos sobre os livros didáticos do Ensino de Sociologia; 8) Estudos sobre a Sociologia da Juventude e o Ensino de Sociologia; 9) Estudos sobre a Sociologia da Educação Pública/Básica; 10) Estudos sobre as Políticas Públicas de Fomento e o Ensino de Sociologia; 11) Estudos de documentos oficiais e legislação educacional; 12) Coletânea de temários/conteúdos estruturantes do Ensino de Sociologia nos livros coletâneas (Trabalho; Violência; Religiáo; Desigualdades Sociais; Gênero; Questôes Étnico-raciais; Sociologia da Informação; Meio Ambiente; Direitos Sociais e Humanos; Inclusão).

IV. Além disso, está especificada, de acordo com a produção simbólica de cada ato coletivo e seus momentos mais marcantes, como os que seguem: I. a reflexão sobre a campanha do retorno do ensino de Sociologia na Educação Básica; II. a reflexão sobre o sentido do veto presidencial de Fernando Henrique Cardoso (2001) ${ }^{5}$; III. as reflexóes em torno da obrigatoriedade do ensino, a partir da Lei no 11.684 , de 2 de junho de 2008; IV. a reflexão sobre o programa nacional dos conteúdos sobre o ensino de sociologia; V. a avaliação crítica da presença do Programa Institucional de Bolsas de Iniciaçáo à Docência (CAPES/PIBID). Enfim, a cada rodada de debates, há uma distinção nas relaçóes de ensino na formaçáo de professores e na Educaçáo Básica, que confere, à produçấo, novos sentidos ao campo à medida que avança a sua capacidade de se autorrefletir sobre a Sociologia das Conflituosidades neles contidos como habitus.

Há um conjunto de desafios que cercarão as novas produçóes dos livros coletâneas, temários e as novas páginas de sua história a partir das lentes do

5 Veto ao Projeto de Lei $n^{\circ}$ 09/2000, aprovado no Congresso Nacional que estabelecia o retorno de Filosofia e Sociologia no Ensino Médio. 
Ensino de Sociologia na Educação Básica. De imediato, é visível a contribuição, o esforço de contextualização entre ensino, escola e seus atores sociais diretamente envolvidos no processo de ensino e aprendizagem e os renovados ares institucionais de produçáo e, no contraponto, os novos saltos quanto à ampliação do efetivo acesso às obras, ainda com baixas tiragens e suas inserçôes em formatos digitalizados. Três tendências dessas produçóes têm se apresentado como rumos muito férteis nesse novo tempo da História do Ensino de Sociologia: a) os livros coletâneas como sínteses dos eventos nacionais e estaduais da área, imprescindíveis, enquanto memória, patrimônio, registros e disseminação da circulação das ideias do subcampo; b) os livros coletâneas no formato "temáticos", o que tem permitido um maior entrelaçamento entre os capítulos, autores, experiências e aprofundamentos teóricos e didáticos; c) as produçóes que partem de projetos institucionais nacionais como o Programa Institucional de Bolsas de Iniciação à Docência (PIBIDs) assim como os laboratórios de ensino das universidades em suas perspectivas locais.

As trilhas abertas a partir das novas produçóes bibliográficas sobre o Ensino de Sociologia na Educação Básica demonstram que o trabalho de pesquisa sobre as próprias produçóes dos cientistas sociais-professores de longe se esgotam. Entre páginas e escritas, as sociologias se renovam; no "espírito de novos tempos", o ensino mostra a cada dia uma atualização exigente e imprescindível. Entre as várias contribuições da área, os livros coletâneas, podem ser ótimos (mas não os únicos) sinalizadores, cujas letras estão sempre em movimento. Rumo ao desbravamento de seus novos códigos e signos sociológicos!

\section{Referências}

BOURDIEU, P. As regras da arte. Sáo Paulo: Companhia das Letras, 1996.

. A economia as trocas lingüísticas. São Paulo: Editora da Universidade de São Paulo, 1998. . O poder simbólico. Rio de Janeiro: Bertrand Brasil, 1998.

. A economia das trocas simbólicas. São Paulo: Editora Perspectiva, 2001.

- Os usos sociais da ciência: por uma sociologia clínica do campo científico. São Paulo: Editora UNESP, 2004.

BRASIL. Legislação Brasileira sobre educação. Brasília: Câmara dos Deputados, edições câmara, 2009. 
MANNHEIM, K. Sociologia da Cultura. São Paulo: Perspectiva, 1974 a.

. Sociologia do Conhecimento. Rio de Janeiro: Zahar Editores, $1974 \mathrm{~b}$.

PULICI, C. Entre sociólogos: versôes conflitivas da "condição de sociólogo" na USP dos anos 1950-1960. São Paulo: Editora da Universidade de São Paulo/Fapesp, 2008.

STONE, L. Prosopografia. Tradução de Gustavo Biscaia Lacerda e Renato Monseff Perissinotto. Revista Sociologia \& Política, Curitiba, v. 19, n. 39, jun. 2011.

VILLAS BOAS, G.. A vocação das Ciências Sociais no Brasil: um estudo da sua produção em livros do acervo da Biblioteca Nacional (1945 a 1966). Rio de Janeiro: Biblioteca Nacional, 2007.

\section{LIVROS COLETÂNEAS SOBRE O ENSINO DE SOCIOLOGIA - 2004/2015}

BRIDI, M. A.; ARAÚJO, S. M.; MOTIM, B. L. Ensinar e aprender Sociologia. São Paulo: Contexto, 2010.

CAINELLI, M. R.; SILVA, I. F. (Org.). O estágio na licenciatura: a formação de professores e a experiência interdisciplinar na Universidade Estadual de Londrina. Londrina: UEL, 2009.

CARVALHO, C. A (Org.). A Sociologia no Ensino Médio. Londrina: EDUEL, 2010.

CARVALHO, L. M. G (Org.). Sociologia e ensino em debate: experiências e discussão de sociologia no ensino médio. Ijuí: Ed. Unijuí, 2004.

COlOGNESE, S. A (Org.). O desenvolvimento da Sociologia no oeste do Paraná. Tempo da Ciência, v. 12, n. 24, p. 145-160, $2^{\circ}$ sem. 2005.

Fronteiras do saber sociológico. Porto Alegre: Evangraf, 2012.

Novas fronteiras para o saber sociológico. Porto Alegre: Evangraf, 2013.

ERAS, L.; FEIJÓ, F. Por uma transposição didática das teorias das Ciências Sociais (Sociologia, Antropologia e Ciência Política): teorizações sobre as práticas de ensino em Ciências Sociais. In: Gonçalves, D. N. (Org.). Sociologia e Juventude no Ensino Médio: formação, PIBID e outras experiências. 1. ed. Campinas: Editora Pontes, 2013, v. 1, p. 87-99.

FERREIRA, L. de F. G. (Org.). Subsídios para a educaçáo em direitos humanos nas ciências sociais. João Pessoa: Editora Universidade da UFPB, 2010.

FIGUEIRO, A. V.; OLIVEIRA, L. F.; PINTO, N. M. Sociologia na sala de aula: reflexôes e experiências docentes no Estado do Rio de Janeiro. Rio de Janeiro: Imperial Novo Milênio, 2012. 
GONÇALVES, D. N. (Org.). Sociologia e Juventude no Ensino Médio: formação, PIBID e outras experiências. Campinas: Editora Pontes, 2013.

HANDFAS, A. OLIVEIRA, L. F. (Org.). A Sociologia vai à escola. Rio de Janeiro: Quartet FAPERJ, 2009.

.; MAÇAIRA, J. P. Dilemas e perspectivas da Sociologia na Educaçáo Básica. Rio de Janeiro: E-papers, 2012.

; .; FRAGA, A. B. Conhecimento escolar e ensino de Sociologia: instituiçóes, práticas e percepçóes. Rio de Janeiro: 7 Letras, 2015.

LIMA, M. A. de S. (Org.). As persistentes desigualdades brasileiras como temas para o Ensino Médio. Londrina: Eduel, 2011.

Experiências e reflexóes na formação de professores. Londrina: UEL, 2012.

. Práticas e Debates na formaçáo de professores de Sociologia/Ciências Sociais. Londrina: UEL, 2013.

Estágio, formaçáo e trabalho docente: experiências das jornadas/cursos do FOPE/ PRODOCÊNCIA. Londrina: UEL, 2014.

.; ARAÚJO, A. L.; FERREIRA, J.; MOTTA, S. C. L. Sugestóes didáticas de Ensino de Sociologia. Londrina: UEL, 2012.

.; VITALIANO, C. R., ALTIANO, F. C., MACHADO, R. P. B. Inclusão: debates em diferentes contextos. Londrina: EDUEL, 2013.

MAESTRI, D. S. M. LDB, DCNs, PCNs e OCNs: uma discussão acerca do papel das Ciências Humanas e da Sociologia no Ensino Médio. In: MEIRELLES, M.; RAIZER, L.; PEREIRA, L. H. (Org.). O ensino de Sociologia no RS: repensando o lugar da Sociologia. Porto Alegre: Evangraf/ LAVIECS, 2013.

MEDIAÇÓES: Revista de Ciências Sociais - Dossiê Ensino de Sociologia, Londrina, v. 12, n. 1, p. 145-160, jan./jun. 2007.

MEIRELlES, M.; RAIZER, L.; PEREIRA, L. H. (Org.). O ensino de Sociologia no RS: repensando o lugar da Sociologia. Porto Alegre: Evangraf/LAVIECS, 2013.

Diálogos entre Pedagogia e Sociologia. Porto Alegre: Evangraf/LAVIEC, 2014.

MORAES, A. Explorando o Ensino - Sociologia. Ministério da Educação, Secretaria de Educação Básica, 2010. v. 15. 
OLIVEIRA, D. D. (Org.). Sociologia e educaçáo em direitos humanos. Goiânia: Fundação de Apoio à Pesquisa na UFG (FUNAPE), 2010.

Sociologia no ensino médio: experiências e desafios. Goiânia: Fundação de Apoio à Pesquisa na UFG (FUNAPE), 2010.

Ensino de Sociologia: currículo, metodologia e formação de professores. Goiânia: UFG/ FUNAPE, 2011.

OLIVEIRA, L. F. (Org.). Sociologia na sala de aula: reflexões e experiências docentes no Estado do Rio de Janeiro. Rio de Janeiro: Imperial Novo Milênio, 2012.

Ensino de Sociologia: desafios teóricos e pedagógicos para as Ciências Sociais. Seropédica, RJ: Editora da UFRRJ, 2013.

OliveIRA, M. de (Org.). As Ciências Sociais no Paraná. Curitiba: Protexto, 2006.

PLANCHEREL, A. A.; OLIVEIRA, E. A. F (Org.). Leituras sobre sociologia no Ensino Médio. Maceió: EDUFAL, 2007.

RAMALHO, J. R.; SOUZA, R. de A. (Org.). Pibid: Memórias de iniciação à docência. Campina Grande: Editora da UFCG, 2013.

SANTOS, A. R. de J. (Org.). Práticas e reflexóes de ensino e pesquisa do projeto PRODOCÊNCIA da UEL. Londrina: Universidade Estadual de Londrina, 2012.

SILVA, I. L. F. (Org.). Cadernos de metodologias de ensino e pesquisa de sociologia: Lenpes laboratório de ensino, pesquisa e extensão de sociologia. SETI-PR, 2009.

SOUSA, F. P. (Org.). Sociologia conhecimento e ensino Florianópolis: Editora em Debate, 2012. VIEIRA, J. G. V.; CUNHA, L. A. Desafios e perspectivas do Ensino e da formaçáo de Professores de Sociologia para o Ensino Médio. Mossoró: UERN, 2014.

Recebido em: 10.07.2015 Aceito em: 20.10.2015 


\section{On the tracks of the collections books: a bibliographical essay}

\section{Abstract}

The production of this bibliographic essay register the balance and handling of the subfield of Sociology of Education in Basic Education revealing a rich production in recent history, themes and productions that reveal transitions looks, maturity and significant changes inserted at school who challenge thought and teacher training in academic and school spheres.

Keywords: Sociology of Education. Basic education. Compilations books. 